\title{
Profissionalização dos professores: (Re)posicionamento nas classificações das profissões
}

Joana Camposi

Escola Superior de Educação de Lisboa, Portugal

Resumo

A educação e formação das populações ocupam nas sociedades contemporâneas uma posição de destaque. A decisão política não dispensa, na atualidade, a medição dos resultados educacionais (Schleicher, 2012). Há, consequentemente, um aumento da exigência relativamente ao desempenho profissional dos professores (Lanthaume, 2006; Schleicher, 2012). O texto que se apresenta inscreve-se numa pesquisa mais alargada sobre professores no sistema educativo português. No processo analítico desenvolvido procurou-se contribuir para o aprofundamento do conhecimento sobre o processo de profissionalização dos professores em Portugal. A análise do grupo profissional dos professores, no quadro do seu processo de profissionalização, ocupou-se centralmente do questionamento em torno da diferenciação e homogeneização interna do grupo profissional, centrando-se analiticamente no (re)posicionamento dos professores nas classificações das profissões. Metodologicamente identificaram-se como fontes fundamentais as classificações das profissões nacionais e internacionais.

Palavras-chave

Professores; Profissionalização; Classificações das profissões 


\section{Introdução: Grupo profissional dos professores como objeto de estudo}

A educação das populações é política, económica e socialmente central para a configuração das sociedades contemporâneas. O desenvolvimento e sistemática monitorização dos sistemas educativos têm sido considerados fundamentais nestas sociedades, o que tem vindo a traduzir-se num aumento da exigência relativa ao desempenho profissional dos professores (Lanthaume, 2006; Schleicher, 2012; Tardif, 2013). Paradoxalmente, a par do reforço do reconhecimento da função social dos professores com a reafirmação da missão social e pública da função docente (Stoleroff \& Santos, 2014), assiste-se a uma crescente precarização das suas condições laborais (Stoleroff \& Pereira, 2009; Tardif, 2013).

A escolha deste grupo profissional para a pesquisa que se apresenta prende-se, por um lado, com a posição de destaque dos docentes no quadro das sociedades contemporâneas, com responsabilidade na promoção do sucesso educativo das populações (Sebastião, 1998; Tardif, 2013), e, por outro, com a necessidade de aprofundamento do conhecimento sobre os grupos profissionais e respetivos processos de profissionalização na sociedade portuguesa (Rodrigues, 2012). Complementarmente, também pela importância de que se reveste o aprofundamento do conhecimento para a tomada de decisão política educativa à escala dos sistemas educativos (Tardif, 2013), das direções das escolas e das instituições de formação de professores, entre outros.

A pesquisa que se apresenta integra-se numa investigação mais alargada, desenvolvida em torno dos professores no sistema educativo português, que procura aprofundar o conhecimento do processo de profissionalização dos professores, lançando um olhar sobre estes profissionais enquanto grupo profissional, tomando a sociologia das profissões como pano de fundo teórico-analítico. A análise do grupo profissional dos professores, no quadro do seu processo de profissionalização no que à interrogação e questionamento em torno dos traços de diferenciação interna do grupo diz respeito, ocupa o presente texto. Teoricamente tomaramse os contributos de autores que defendem a adoção de uma abordagem dinâmica da profissionalização, ou seja, a profissionalização enquanto processo não linear e cumulativo entre ocupação e profissão, entendida como 
percurso dos grupos profissionais que não se faz linearmente; ou seja, sem que haja um conjunto de etapas predefinidas e orientadas para um único e último objetivo: o profissionalismo. Numa etapa anterior da pesquisa, procedeu-se à identificação das fontes fundamentais das estatísticas oficiais da educação para enquadramento genérico do processo de profissionalização dos professores em Portugal, com desenvolvimento analítico em torno dos indicadores socioprofissionais. Os resultados alcançados permitiram, genericamente, aprofundar e "afinar" a focagem das (principais) tendências e especificidades do processo de profissionalização dos professores em Portugal (Campos, 2014).

Para o desenvolvimento analítico em torno do processo de profissionalização do grupo profssional dos professores, mais concretamente o (seu) (re)posicionamento nas classificações das profissões, consideraramse as classificações das profissões internacionais (International Standard Classification of Occupations de 1988 - ISCO1988; International Standard Classification of Occupations de 2008 - ISCO2008) e nacionais (Classificação Nacional das Profissões de 1994 - CNP94 e Classificação Portuguesa das Profissões de 2010 - CPP2010). Metodologicamente tomaram-se as classificações das profissões por constituirem uma das dimensões de análise do processo de profissionalização, na medida em que as classificações das profissões refletem e fixam, em certo sentido, o entendimento socialmente construído acerca do perfil, mandato, função da atividade e estatuto de cada grupo profissional. Por outro lado, as classificações das profissões ao fixarem esse entendimento, determinam, num certo período de tempo, o que é transversalmente considerado, logo esperado, como o dever e o tipo de natureza do conhecimento mobilizado e ação profissional dos elementos de cada grupo profissional e do grupo como um todo.

Analiticamente, procurou-se identificar inicialmente as alterações de posicionamento do grupo profissional na atual classificação das profissões em Portugal (2010), face à anterior (1994), considerando-se as permanências e alterações dos grandes grupos e a classificação dos subgrupos. Numa segunda fase, pretendeu-se analisar os descritores associados a cada subgrupo profissional, para comparação intra-grupo na atual classificação e em face aos respetivos descritores na classificação anterior. A análise final permitiu assim combinar uma dimensão diacrónica relativa às alterações 
identificadas na mais recente classificação das profissões, face à anterior, com uma dimensão sincrónica, possibilitando uma análise comparativa das distinções entre subgrupos de professores nas classificações.

\section{Profissionalização: Necessidade de revisitação do conceito}

No que comummente se designa por 'sociedade do conhecimento' tem sido crescente a retoma da importância dos grupos profissionais (Carvalho, Santiago, \& Caria, 2012). A par desse recrudescimento, assiste-se ao novo fôlego que o estudo sobre grupos profissionais tem vindo a ganhar na sociologia das profissões. Profissão e profissionalismo são na atualidade referências valorizadas no imaginário social dos grupos profissionais (Carapinheiro \& Rodrigues, 1998; Evetts, 2003), por oposição ao amadorismo, ao assalariamento e ao funcionalismo. A (crescente) profissionalização constitui uma aspiração para muitos grupos profissionais, seja pelo poder e prestigio, seja pela autonomia, que the estão associados (Carapinheiro \& Rodrigues, 1998; Evetts, 2003).

A análise em torno do grupo profissional dos professores é reveladora da necessidade de retoma da discussão do conceito de profissionalização e outros afins, indo ao encontro do desafio lançado por Estrela (2014), num artigo relevante para o relançamento do debate. Anteriormente, Abbott (1988, 1991) assinalou a necessidade de concetualização de uma abordagem dinâmica para a análise do desenvolvimento dos grupos profissionais, recuperando os trabalhos de Wilensky (1964) no que à discussão do processo de profissionalização constitui avanço (Rodrigues, 1997, 2012). Wilensky (1964), também movido pelo reconhecimento da necessidade de melhor se estabelecerem as fronteiras do conceito, avançou a ideia de profissionalização associada à sequencialidade de etapas percorridas por um grupo (inicialmente) ocupacional até atingir a etapa última, a do profissionalismo. A proposta de Wilensky (1964), à época, permitiu ultrapassar a excessiva dicotomização das principais correntes teóricas (Gonçalves, 2007/08) ao incorporar, por um lado, os contributos da perspetiva interacionista, sublinhando o carácter processual da profissionalização (Rodrigues, 1997), e, por outro, a ideia de acumulação quantitativa de elementos definidores de um grupo profissional, da perspetiva funcionalista. 
A adoção da perspetiva de profissionalização como processo não linear de cumulatividade entre ocupação e profissão fez abandonar um conjunto de propostas que assentavam na classificação das profissões com posicionamentos terminologicamente identificados como "semiprofissões" e "quase-profissões"1, amplamente importados para as análises produzidas no quadro de outras áreas como a educação. A definição de profissão não se prende com o que prescritivamente se entende ser os atributos que garantam a obtenção de uma "chancela" que distinga as profissões, das semiprofissões, das ocupações. É sobretudo relevante a compreensão das condições e mecanismos que traçam os percursos dos grupos profissionais, por um lado, assim como o reconhecimento de diferentes segmentos de subgrupos no seio dos grandes grupos, por outro. O reconhecimento da não linearidade dos percursos prende-se também com as estratégias de definição de fronteiras entre grupos, de apropriação de exclusividade para o respetivo mandato, assim como as diferentes modalidades de que se recobrem os movimentos associativos de cada grupo profissional e o respetivo posicionamento face aos outros grupos.

Atualmente a sociologia das profissões integra diversos contributos resultantes da ultrapassagem de "velhas" dicotomias e do avanço para quadros teórico-analíticos mais complexos (Dubar, 1991; Gonçalves, 2007/08; Rodrigues, 1997, 2012). Os trabalhos de Abbott (1988) são neste âmbito incontornáveis, em grande medida por terem tornado possível esses avanços ao sistematizarem os contributos teórico-metodológicos provenientes quer dos quadros teóricos funcionalistas, quer interaccionistas, assim como das teses do poder profissional (Gonçalves, 2007/08). Para a presente análise tomamos por isso a proposta de Abbott $(1988,1991)$ como pano de fundo teórico-analítico central. Numa breve sistematização da sua proposta, procuraremos situar para cada um dos três níveis de análise definidos pelo autor o potencial analítico relativo ao grupo profissional dos professores. $\mathrm{O}$ primeiro nível prende-se com a análise do processo e das condições do estabelecimento efetivo de uma profissão e da manutenção da sua jurisdição; o segundo relaciona-se com as fontes de mudança operadas no interior do sistema das próprias profissões; e o terceiro diz respeito às fontes de mudança localizadas no exterior do sistema das profissões (Abbott, 1988, 1991). 
Abbott (1988) define ainda três campos de processamento das pretensões ou disputas de jurisprudência profissional: o sistema legal, a opinião pública e as situações de trabalho. É sobretudo no primeiro nível que se distingue a importância do conhecimento, mais concretamente do conhecimento científico. A necessidade deste tipo de conhecimento para a fixação da jurisprudência das profissões é considerado fundamental, nomeadamente para a afirmação e reconhecimento social das profissões. Parte significativa do reconhecimento social assenta na identificação de um sistema de conhecimento que é formalizado e considerado exclusivo daquele grupo profissional, legitimando o trabalho desses profissionais pelo desenvolvimento de "novos" conhecimentos e "novas práticas" profissionais. A produção e uso do conhecimento profissional em exclusivo fixa a jurisdição e mantém-na².

No caso dos professores é particularmente desafiante ler o grupo a partir desta lente. Nas suas situações de trabalho, assim como no campo da opinião pública, os professores precisam de marcar as "fronteiras'"' e "interdependências" face a outros grupos profissionais como os psicólogos, assistentes sociais, educadores sociais, animadores socioculturais, entre outros. Nessa fixação, reforçam a sua constituição enquanto grupo profissional. Contudo, a distribuição das posições no sistema profissional não é horizontal e harmonioso, distinguindo-se entre produtores e executores, com distinções internas e conflitualidades. A análise desenvolvida no segundo nível reforça precisamente esta ideia, ou seja, na proposta de Abbott há a afirmação de uma dinâmica e equilíbrio do próprio sistema de profissões como resultado de forças externas e internas. Nas forças externas consideram-se as alterações gerais que são transversais aos grupos profissionais e reconfiguradoras das necessidades e exigências dos clientes, como por exemplo as alterações tecnológicas, organizacionais, assim como de ordem dos fatores culturais ou naturais (Rodrigues, 1997). A profissão de professor constitui uma boa ilustração, na medida em que tem vindo a ser desafiada pela globalização da inovação tecnológica, com a crescente massificação do acesso a fontes de conhecimento e consulta de informação (Lanthaume, 2006; Tardif, 2013), assim como pela presença de um conjunto de "clientes" (alunos, pais, comunidades) crescentemente diversos. Nos relatórios da OCDE os efeitos dessas pressões externas são identificados, 
grosso modo, como os principais desafios colocados aos professores no século XXI (Schleicher, 2012).

As forças internas são identificadas por Abbott (1988) como mudanças, seja no desenvolvimento de novos conhecimentos, seja na estrutura social das profissões. Um primeiro tipo de diferença interna prende-se com o estatuto intraprofissional. Na distribuição interna dos profissionais, Abbott (1988) entende que uns se aproximam da produção de conhecimento profissional, sobretudo na qualidade de académicos, consultores, entre outros, ocupando as posições mais elevadas do estatuto profissional. Os outros posicionam-se mais distanciadamente da produção do conhecimento, aproximando-se sobretudo da aplicação do mesmo, isto é, dos "clientes" (Abbott, 1988). Na análise sobre os professores é relevante a distinção entre os que se encontram em contexto profissional no desempenho de funções docentes, com relação de proximidade com os alunos, e outros com funções dirigentes e/ou técnicos superiores nas estruturas ministeriais ou sindicais, por exemplo. Distinguem-se ainda os que se posicionam quase como outsiders da escola, mas que assumem sobretudo a função de produtores, considerados como especialistas e/ou os académicos (experts). Outro tipo marca-se pela diferenciação da "clientela": os profissionais distinguem-se pelo perfil de clientes que atendem, seja pelas suas posições, recursos ou tipo de problemas, seja pelas exigências que colocam. No caso dos professores, é diferenciado o reconhecimento do exercício profissional entre setores de ensino, ciclos de ensino e ainda vias de ensino, por exemplo. Para os professores, a diferenciação interna do grupo passa, também, por este mecanismo de distinção, contudo (fortemente) mitigado pelo efeito da estatização do seu estatuto, isto é, por ter, no caso da sociedade portuguesa, como entidade patronal quase exclusivamente o Estado (Campos, 2014; Nóvoa, 1995) ${ }^{3}$.

Ao definir o espaço profissional como um "sistema de profissões", Abbott (1988) sublinha a importância da afirmação de cada profissão por oposição a outros profissionais, por vezes conflitual, no sentido de fixar a sua jurisdição, ou seja, a necessidade de definição de fronteiras de ação e de identidade profissionais (Evetts, 2003). Esta ideia remete para o conceito de poder, como conceito transversal à análise das profissões e dos grupos profissionais, que contribuiu para uma compreensão mais aprofundada das 
condições de profissionalização dos grupos, ao permitir desvendar as especificidades de cada grupo, nomeadamente pela definição das fronteiras entre grupos, das condições de acesso aos grupos, da possibilidade de monopolização da ação profissional, e também pelo fundamento e legitimação para a regulação e regulamentação das práticas profissionais. Embora o poder não seja considerado um elemento essencial no modelo de Abbott (Rodrigues, 1997), está presente e é importante para a análise. O poder na proposta deste autor "joga-se" nos três campos de jurisdição. No legal, por via das pressões para as licenças (do Estado) para a legitimação para o exercício profissional (em exclusivo), e com (ou sem) regulação ética e deontológica. No plano de relação com o público, através de diferentes formas, nomeadamente pela visibilidade conferida pela comunicação social, que contribui para o reforço ou recuo do reconhecimento social das profissões. No plano das situações de trabalho, por via do desempenho profissional, com o controlo de uma linguagem que se mantém exclusiva face aos clientes e a outros de outras áreas profissionais (Abbott, 1988). No caso dos professores, nas suas situações de trabalho é comum identificar-se nas investigações desenvolvidas, sobretudo na sociologia da educação, o estabelecimento de fronteiras simbólicas com as famílias e encarregados de educação, nomeadamente os que se distanciam mais fortemente da cultura escolar (Abrantes \& Sebastião, 2010; Sebastião, 1998, 2009).

O poder tinha sido anteriormente considerado em propostas de outros autores relevantes para a atual definição de profissionalização, destacandose Larson (1977) pelo contributo que trouxe com a definição dos monopólios profissionais. $\mathrm{Na}$ sua proposta, as profissões são entendidas como instituições que visam reforçar a sua posição de poder, aumentar o seu prestígio e garantir os seus privilégios (Rodrigues, 2012, p. 81). A estratégia dos diversos grupos profissionais passaria, assim, pela sua afirmação através do reconhecimento das suas competências. A importância das associações profissionais ganha particular relevância no pensamento desta autora (Larson, 1977) sobretudo pela posição que as mesmas assumem na criação e controlo dos monopólios profissionais. O poder de decisão sobre o sistema de licenças e o registo de certificação para o exercício da atividade profissional permite às associações obter o reconhecimento interno e externo da respetiva profissão. O processo de autorregulação do acesso dos 
profissionais aos grupos por via das associações implica que as mesmas negoceiem com o Estado, na posição de primeiras responsáveis pela definição das competências necessárias para o exercício profissional. A ideia de fechamento é, nesta proposta, entendida como conjunto de estratégias através das quais os grupos procuram garantir a sua posição no mercado, embora nos textos posteriores a autora tenha relativizado a ideia de monopólio: "Un certain controle de l'accés aux titres et diplomes, lié à la protection de la rarité (sinon nécessairement du monopole), fait partir intégrante de cette notion de la professionnalisation" (Larson, 1988, p. 28). A profissionalização, segundo Larson (1988), corresponde assim ao processo pelo qual os grupos profissionais controlam o (seu) mercado, procurando manter a exclusividade da sua ação, mantendo os profissionais dos outros grupos como os "de fora", no sentido de tentar manter um monopólio protegido.

A importância do papel desempenhado pelas associações profissionais na formação da profissão e na defesa do prestígio e do mercado profissional é também assinalada na análise de Lousada (2004) relativa à evolução das associações profissionais, designadamente de professores, e associações sindicais de professores em Portugal. Analiticamente, a autora sublinha a existência de situações de rivalidades e tensões no interior do próprio grupo, à semelhança de outros grupos profissionais (Lousada, 2004). No caso dos professores em Portugal, a relevância do associativismo profissional para o processo de profissionalização do grupo pauta-se por especificidades que merecem ser mais detalhadamente discutidas e analisadas (Campos, 2014; Lousada, 2004).

\section{Profissionalização dos professores em Portugal: (Re)posicionamento na classificação das profissões}

Tardif (2013), num artigo de balanço, reflete sobre o processo de profissionalização dos professores nos últimos 30 anos, considerando que se trata da transformação mais substancial e necessária ocorrida na educação neste lastro de tempo. A análise sobre o caso português vai ao encontro dos estudos sobre a profissionalização dos professores noutros países, na medida em que, salvaguardando as especificidades e particularidades nacionais, é comum a forte dependência da tutela estatal e o caráter processual da 
profissionalização deste grupo, à semelhança de outros grupos (Bourdoncle, 1993). Em Portugal, o processo de profissionalização dos professores tem sido marcado por especificidades e fragilidades, identificadas e analisadas por diversos autores (Nóvoa, 1995; Roldão, 2007; Sarmento, 1994), que se prendem com o processo de democratização do sistema educativo português (Campos, 2014), e tem-se pautado por uma relativa exterioridade dos profissionais do grupo face à produção e regulação da produção do (seu) conhecimento profissional (Roldão, 2007) e, ainda, face aos processos de regulação da sua prática profissional (Campos, 2014), como consequência, entre outros fatores, da forte estatização do grupo (Nóvoa, 1995; Sarmento, 1994).

No que se refere à manutenção do campo específico do grupo profissional, mais concretamente a definição da credenciação e certificação necessárias para o exercício profissional, assistiu-se no caso português a um conjunto de alterações assinaláveis (Campos, 2014), considerando-se a mais relevante a definição, em 2007, de um nível de qualificação comum referente à habilitação para a docência para os docentes de todos níveis de ensino, exceto o superior (Afonso, 2008; Campos, 2002). As condições de acesso não têm sido definidas pelas associações profissionais em exclusivo, mas resultam, sim, de negociação mais alargada com o Estado, que assume neste caso a tutela quase monopolística do sistema educativo e, consequentemente, da contratação e recrutamento dos professores. Embora se trate de um movimento com acentuada longevidade (Lousada, 2004; Nóvoa, 1987), nos últimos anos o associativismo profissional dos professores ganhou particular visibilidade pública, passando a ser ponto de agenda política e mediática4. No caso das associações sindicais, destaca-se os movimentos de contestação dos professores em torno das revisões do Estatuto da Carreira Docente (2007) e do Modelo de Gestão e Direção das Escolas (2008) (Pereira, 2009; Resende, Gouveia, \& Beirante, 2014; Stoleroff \& Santos, 2014). No caso das associações profissionais, destaca-se a discussão pública das alterações aos programas de Ensino Básico, assim como à avaliação dos alunos e professores, mais concretamente os exames de final de ciclo de ensino (2012) e a prova de acesso ao sistema de ensino público para os professores em início de carreira (2013/2014). Embora seja consensual o entendimento da profissionalização dos professores em 
Portugal como um processo atravessado por tensões e conflitualidades (Nóvoa, 1995; Roldão, 2007; Sarmento, 1994), permanence, contudo, no discurso do senso comum a ideia de um grupo profissional homogéneo.

\section{Classificações das profissões}

Pode afirmar-se que as sociedades constroem socialmente as classificações, mas as classificações também constroem socialmente as sociedades; tomando as palavras de António Firmino da Costa (1998), "as classificações sociais são intrinsecamente constitutivas das sociedades" ( $p$. 65). As classificações pautam-se, por isso, por elevada transversalidade, porque "perpassam pelos quadros de relacionamento social, em toda a sua espessura (...) enquanto, nomeadamente, classificações eruditas, teóricas, técnicas ou institucionais. Elas estão presentes na vida social corrente, nas interacções quotidianas e no relacionamento informal" (Costa, 1998, p. 65). As classificações sociais assumem essa transversalidade na medida em que são "padrões de cultura socialmente partilhados, são modos de perceber o mundo, são instrumentos de acção social" e são, também, "objecto de transmissão" (Costa, 1998, p. 68). É neste sentido que nos parece pertinente analisar a importância das posições dos professores nas classificações profissionais, seja nas distinções internas, seja nos processos de (re)posicionamento verificados na última revisão das classificações das profissões.

Costa (1998) defende que as classificações se inserem nas relações e nos processos sociais, assumindo, entre outras, também as dimensões do poder e da dominação. No seu texto de discussão em torno das classificações sociais, utiliza como ilustração os processos de luta e confronto entre diversos protagonistas e interessados na definição e posicionamento das profissões e ocupações nos sistemas de classificação internacionais das profissões. Como refere o autor, "as classificações profissionais resultam de um processo social alargado, em parte de cunho informal, em parte de carácter institucional, envolvendo uma multiplicidades de agentes, atravessado por lutas de classificações" (Costa, 1998, p. 73). Na revisão das classificações das profissões participam não só os técnicos e as organizações que assumem a responsabilidade da produção estatística, internacional e nacional e os peritos, mas também outros protagonistas, como os sindicatos, as 
organizações profissionais e outras entidades e interessados, em geral (Lima, Dores, \& Costa, 1991).

Em 2008 foi publicada a Classificação Internacional das Profissões (CITP/2008) atualmente em vigor (Quadro 1). Em Portugal, a adoção da CITP/2008 implicou a revisão da Classificação Nacional das Profissões de $1994(\mathrm{CNP} / 94)^{5}$, com a publicação de uma nova classificação CPP (Classificação Portuguesa das Profissões), em 2010 (CPP2010)6 ${ }^{6}$. Na anterior classificação registava-se uma relativa ambiguidade na classificação de algumas das profissões, que foi na versão de 2010 atenuada, dando particular atenção à complexidade das funções efetivamente exercidas pelos profissionais dos diversos grupos, e consequente grau de competência que as mesmas implicam. Esta atualização inscreve-se, em grande medida, nas tendências que se têm vindo a afirmar nas sociedades contemporâneas 7 . Relativamente aos conceitos e definições de base utilizadas na CPP2010 houve a tentativa de, no essencial, manter o que na classificação internacional (ISCO 2008) se fixou. Assim, os conceitos centrais mantiveram-se: posto de trabalho, tarefa, profissão, nível de competências e competência especializada (CPP2010).

\begin{tabular}{|c|c|}
\hline 1 & Representantes dos poderes legislativos e executivo, diretores e gestores executivos \\
\hline 2 & Especialistas das atividades intelectuais e científicas \\
\hline 3 & Técnicos e profissões de nível intermédio \\
\hline 4 & Pessoal administrativo \\
\hline 5 & Trabalhadores dos serviços pessoais, de proteção e segurança e vendedores \\
\hline 6 & Agricultores e trabalhadores qualificados da agricultura, da pesca e da floresta \\
\hline 7 & Trabalhadores qualificados da indústria, construção e artífices \\
\hline 8 & Operadores de instalações e máquinas e trabalhadores da montagem \\
\hline 9 & Trabalhadores não qualificados \\
\hline
\end{tabular}

Quadro 1 - Identificação dos Grandes Grupos de Profissões ISC02008/CPP2010

As alterações gerais enunciadas na CPP2010 são extensas e decorrentes da necessidade de harmonização entre a classificação portuguesa e a internacional (CITP/2008). Relativamente aos professores, 
das alterações introduzidas na CPP2010, destaca-se a que se prende com a distribuição destes profissionais anteriormente entre dois Grandes Grupos: 2 e 3, e que agora se encontram reunidos no Grande Grupo 2 dos Especialistas das atividades intelectuais e científicas. Esta alteração acompanha a tendência geral, ou seja, o decréscimo do número de profissões, contra o aumento dos classificados nos intervalos anteriores.

Os professores viram esbater-se a diferenciação da sua distribuição entre Grandes-Grupos, na CPP2010, face à anterior (Quadros 2 e 3). Esta alteração traduziu-se numa aproximação da classificação nacional à internacional, na medida em que os professores se encontravam já na anterior classificação internacional (ISCO 1988) reunidos no mesmo Grande Grupo (2). Na classificação nacional CNP/1994 os professores do ensino superior, do ensino secundário e dos $2^{\circ}$ e $3^{\circ}$ ciclos do ensino básico posicionavam-se no Grande Grupo 2, definidos genericamente como: "Os especialistas das profissões intelectuais e científicas que desenvolvem conhecimentos ou aplicam conceitos e teorias científicas ou artísticas, transmitem-nos de forma sistemática através do ensino ou dedicam-se a todas as actividades atrás descritas" (CNP94).

As saídas do Grande Grupo 3 resultaram, sobretudo, do reforço da hierarquia das qualificações, associada à complexidade das funções efetivamente exercidas e, consequentemente, ao tipo de competências profissionais necessárias para o desempenho profissional. A complexidade e especificidade de tais competências implicaram, por isso, um aumento de exigência da certificação para o exercício das funções profissionais. Em sentido mais alargado, esta alteração inscreve-se no reconhecimento social da necessidade e centralidade dessas competências e funções profissionais. Tal parece ser a situação dos professores dos níveis de ensino de iniciação, a par de outras profissões similares, que sofreram o mesmo tipo de trajetória. 


\begin{tabular}{|c|c|c|c|c|}
\hline \multirow[t]{2}{*}{2} & \multirow[b]{2}{*}{23} & & & Especialistas das Profissões Intelectuais e Científicas \\
\hline & & & & Docentes do Ensino Secundário, Universitário e Profissões similares \\
\hline & & 231 & 2310 & Docentes do Ensino Universitário e Estabelecimentos do Ensino Superior \\
\hline & & & 2310.05 & Professor do Ensino Superior \\
\hline & & 232 & 2320.05 & Docentes do Ensino Básico ( $2^{\circ}$ e $3^{\circ}$ ciclos $)$ e do Ensino Secundário \\
\hline & & 235 & & $\begin{array}{l}\text { Docentes do Ensino Superior, Básico, Secundário e similares não } \\
\text { classificados em outra parte }\end{array}$ \\
\hline & & & 2351 & Outros especialistas do ensino \\
\hline & & & 2351.05 & Técnico de formação \\
\hline & & & 2351.10 & Técnico de reeducação \\
\hline & & & 2352.05 & Inspetores de Educação \\
\hline & & & 2359.05 & Formador \\
\hline & & & 2359.10 & Professor do Ensino Vocacional Artístico \\
\hline & & & 2359.15 & Professor de Gimno e Desportiva \\
\hline 3 & & & & Técnicos e Profissionais de Nível Intermédio \\
\hline & 33 & & & Profissionais de Nível Intermédio do Ensino \\
\hline & & 331 & & Docentes dos ensino primário e pré-primário \\
\hline & & 332 & & Educadores de Infância \\
\hline & & 333 & & Docentes do Educação Especial \\
\hline & & & 3331.05 & Professor de Educação Especial - Área da deficiência visual \\
\hline & & & 3331.10 & Professor de Educação Especial - Área da deficiência auditiva \\
\hline & & & 3331.15 & Professor de Educação Especial - Área da deficiência mental \\
\hline
\end{tabular}

(Fonte: CNP94)

Quadro 2 - Professores na Classificação Nacional das Profissões (CNP1994) 


\begin{tabular}{|l|l|l|l|l|}
\hline 2 & & & & Especialistas das actividades intelectuais e científicas \\
\hline & 23 & & & Professores \\
\hline & & 231 & 2310.0 & Professor dos ensinos Universitário e Superior \\
\hline & & 232 & 2320.0 & Professor dos Ensinos Tecnológico, Artístico e Profissional \\
\hline & & 233 & 2330.0 & Professores dos Ensinos Básico $\left(2^{\circ}\right.$ e $3^{\circ}$ ciclos $)$ e Secundário \\
\hline & & 234 & & Professor do Ensino Básico $\left(1^{\circ}\right.$ ciclo $)$ e Educadores de Infância \\
\hline & & & 2341.0 & Professor do Ensino Básico $\left(1^{\circ}\right.$ ciclo $)$ \\
\hline & & & 2342.0 & Educadores de Infância \\
\hline & & & 2351.0 & Especialista em Métodos de Ensino ${ }^{\star *}$ \\
\hline & & & 2352.0 & Professor de Ensino Especial \\
\hline & & & 2353.0 & Outros Professores de Línguas \\
\hline & & & 2355.0 & Outros Professores de Artes \\
\hline & & & 2356.0 & Formador em Tecnologias de Informação \\
\hline
\end{tabular}

(Fonte: CPP2010)

* Inclui Inspetores de Educação

**A análise dos professores classificados como "Outros Especialistas do Ensino" e os "Professores do Ensino Especial" e outros, não se inclui no presente texto, considerando-se provisoriamente que a sentido desta diferenciação interna vai, em certa medida, ao encontro do que Estrela (2014) define como as "profissionalidades especificas" e "profissionalidades emergentes".

\section{Quadro 3 - Professores na Classificação Portuguesa das Profissões} (CPP2010)

As alterações relativas aos níveis de qualificação da certificação para a docência estabeleceram-se, em Portugal, no âmbito do processo de revisão da LBSE em 1997, com a equiparação entre níveis de ensino dos níveis de qualificação para a certificação de habilitação para a docência. Até esta data, era exigido o grau de licenciatura apenas aos professores do ensino secundário e $3^{\circ}$ CEB (Afonso, 2008; Campos, 2002). Em 2007, com a adoção do Tratado de Bolonha, foi estabelecido como nível de qualificação para a certificação da habilitação para a docência o $2^{\circ}$ ciclo (mestrado), correspondendo $01^{\circ}$ ciclo à formação generalista e o seguinte à especialização e habilitação específica para a docência. A oferta formativa alterou-se, com a possibilidade de certificação em instituições distintas. No que diz respeito às instituições de formação, é analiticamente relevante a distinção entre a formação para a docência do subsetor universitário, que pode oferecer cursos de formação a docentes do pré-escolar ao secundário, e as instituições do subsector politécnico, que formam docentes até ao $2^{\circ}$ 
CEB (Afonso, 2008; Campos, 2002). Aos docentes do ensino superior os níveis de qualificação exigidos são de nível superior, como já eram na classificação anterior, mas sem qualquer exigência no que diz respeito à certificação de habilitação para a docência.

\section{Professores do Ensino Superior: Universitário e politécnico}

A reunião dos professores no mesmo grupo constitui a mudança mais evidente, embora as alterações encontradas com a publicação da CPP2010 não se esgotem nesse reposicionamento. Há mudanças internas que merecem ser consideradas e que se evidenciam na análise dos descritivos das funções e tarefas atribuídas a cada subgrupo. No topo, na posição 231 , encontram-se os professores dos ensinos universitário e superior. Embora se distingam, na designação, os universitários de outros, mais indefinidos, e onde se incluem os docentes do ensino politécnico, passam, na atual classificação, a ter as mesmas tarefas e funções, como se pode ler no texto relativo a esta posição (2310.0):

Compreende as tarefas e funções do professor dos ensinos universitário e superior que consistem, particularmente, em: Ministrar ensinamentos universitários e superiores; Conceber e modificar currículos e preparar cursos de acordo com os seus requisitos; Preparar e conduzir seminários, conferências e experiências de laboratório; Supervisionar trabalho prático e experimental executado pelos estudantes; Administrar, avaliar e marcar testes e exames; Dirigir a investigação de pós-graduação de estudantes ou membros do departamento; Investigar e desenvolver teorias, conceitos e métodos para aplicação na actividade económica; Preparar livros, documentos e artigos escolares; Participar em encontros no departamento ou faculdade. (CPP2010)

À semelhança da classificação de 1994, é expressa a função de produção de conhecimento fixada nas funções docentes, destacando-se a pesquisa, a investigação e a publicação. Novamente, atribui-se a estes profissionais a responsabilidade de definir curricularmente os cursos de formação superior.

\section{Professores do Ensino Tecnológico, Artístico e Profissional}

Uma alteração face à anterior classificação prende-se com a introdução de uma entrada específica para os professores que se ocupam do ensino tecnológico, artístico e profissional (2320.0), em parte como 
consequência da afirmação de vias de ensino diferenciadas no sistema e no reconhecimento da especificidade destes domínios de conhecimento. O descritivo indica que esta posição

[c]ompreende as tarefas e funções do professor dos ensinos tecnológico, artístico e profissional que consistem, particularmente, em: Ministrar ensinamentos na área tecnológica, artística ou profissional em estabelecimentos de ensino secundário e instituições de educação para adultos; Desenvolver e planear conteúdos para cursos, currículos e métodos de instrução; Determinar necessidades de instrução para estudantes ou trabalhadores e estabelecer ligação com os indivíduos, indústria e outros sectores para assegurar programas educativos ajustados; Apresentar trabalhos e coordenar debates para aumentar os conhecimentos e competências dos estudantes; Instruir e monitorizar estudantes na utilização de ferramentas, equipamentos e materiais e na prevenção de danos; Avaliar trabalho de estudantes para determinar progressos e fazer sugestões de melhoria; Administrar testes orais, escritos e de desempenho para medir progressos e avaliar a eficácia da instrução; Conduzir sessões de treino sobre trabalho, para ensinar e demonstrar princípios, técnicas e métodos. (CPP2010)

A possibilidade de exercerem em dois níveis distintos do sistema, superior e secundário, associada à especificidade de saberes, coloca estes professores num plano distinto dos anteriores e posteriores na classificação. Assim, a distinção deste subgrupo afirma-se no carácter técnico dos saberes, na dimensão profissionalizante da formação em que se encontram envolvidos e, ainda, na clara referência à articulação entre a formação e o mercado de trabalho, em concreto com o setor da indústria.

\section{Professores do Ensino Secundário e $2^{\mathrm{a}}$ e $3^{\circ} \mathrm{CEB}$}

$\mathrm{Na}$ posição seguinte encontram-se os professores do ensino secundário e dos $2^{\circ}$ e $3^{\circ}$ ciclos do ensino básico (2330.0), que, face à classificação anterior, perderam a função associada à preparação profissional dos alunos, que é na atual classificação atribuída ao subgrupo anterior. Outra alteração de fundo prende-se com a redução da função docente dos profissionais destes níveis de ensino à sua especialização numa "matéria", sendo anteriormente identificados como especialistas em didáticas específicas. Na classificação de 2010 há um reforço da dimensão pedagógica, em detrimento da didática; como se pode ler no descritivo respetivo: 
[esta posição] compreende as tarefas e funções do professor dos ensinos básico ( $2^{\circ}$ e $3^{\circ}$ ciclos) e secundário que consistem, particularmente, em: Ministrar ensinamentos em estabelecimentos de ensino básico $\left(2^{\circ}\right.$ e $3^{\circ}$ ciclos $)$ e secundário, utilizando métodos pedagógicos e técnicas apropriadas; Elaborar planos de lições, tendo em atenção a complexidade dos assuntos e as características do grupo a que se destinam; Propor temas para discussão e orientar trabalhos para incentivar o interesse, a participação e o espírito crítico dos alunos; Recolher elementos, informar sobre bibliografia a consultar e visitas de estudo a efectuar; Acompanhar e orientar os alunos na execução de trabalhos práticos; Avaliar a evolução do aluno com base na participação, execução de trabalhos práticos, provas escritas e orais, assiduidade e do comportamento; Elaborar relatórios dos alunos para a direcção da escola e/ou encarregados de educação; Organizar e/ou participar em actividades extraescolares. (CPP2010)

\section{Professores do $1^{\circ} \mathrm{CEB}$}

Por fim, os professores do $1^{\circ}$ ciclo do ensino básico e os educadores de infância, que na atual classificação se encontram no mesmo Grande Grupo, 2, distinguindo-se dos restantes professores do ensino básico e secundário, classificados no subgrupo 234, pela "especial incidência na preparação do programa de aprendizagem, ensino ao nível do $1^{\circ}$ ciclo e planeamento de actividades para facilitar o desenvolvimento das crianças" (CPP2010). Mais concretamente, os professores do $1^{\circ}$ ciclo do ensino básico encontram-se classificados na posição 2341.0, que

[c]ompreende as tarefas e funções do professor do ensino básico $\left(1^{\circ}\right.$ ciclo) que consistem, particularmente, em: Ministrar ensinamentos em estabelecimentos do ensino básico, sobre noções de aritmética, gramática, leitura, história e outras, utilizando métodos e técnicas apropriados; Elaborar planos de lições tendo por base os ensinamentos a transmitir, a metodologia a utilizar, a dificuldade dos assuntos e o grupo a que se destinam; Seleccionar temas susceptíveis de despertarem o interesse e o espírito de imaginação dos alunos; Orientar e avaliar a evolução dos alunos pela participação individual ou em grupo e pelos trabalhos práticos e provas escritas e orais das matérias em estudo; Acompanhar o comportamento dos alunos e transmitir noções elementares de comportamento social; Desenvolver programas de alfabetização de adultos. (CPP2010)

O centramento da ação docente na dimensão pedagógica é, tal como na anterior classificação, o elemento distintivo deste grupo, enfatizando-se a função de iniciação dos alunos nos domínios de saber considerados fundamentais, como a leitura, a escrita, a aritmética, a gramática, a história, e 
outros, complementando-se ainda com o "despertar" do "interesse" e "espírito de imaginação". É marcante o reconhecimento da função socializadora da sua ação, sendo elementos distintivos dos docentes deste nível de ensino a planificação da atividade letiva e a necessidade de adequação metodológica ao público discente.

\section{Educadores de Infância}

Relativamente à atividade dos educadores de infância, na classificação de 2010 (tal como na anterior) define-se em torno da "criança", e já não do "aluno", no sentido do seu desenvolvimento global, e nem tanto nos processos de aprendizagem. O que é comum a todos os docentes em posições anteriores - "ministra ensinamentos..." - não se encontra no descritivo desta posição, ganhando relevância a designação de educador de infância, face ao professor de determinado nível ou via de ensino. Os verbos que indicam o centro da sua ação são ilustrativos da distinção: "estimular", "acompanhar", "orientar", "promover". Assim, considera-se na atual classificação que a ação do educador de infância (2342.0)

[c]ompreende as tarefas e funções do educador de infância que consistem, particularmente, em: Promover actividades que ocupem e incentivem o desenvolvimento global da criança (físico, psíquico, social, etc.); Orientar actividades e exercícios de coordenação, atenção, memória, imaginação e raciocínio para incentivar o desenvolvimento psico-motor da criança; Promover expressões plásticas, musicais, corporais da criança e despertá-la para o meio em que está inserida; Estimular o desenvolvimento sócio-afectivo da criança, promovendo a segurança, auto-confiança, autonomia e respeito; Acompanhar a evolução da criança e estabelecer contactos com os pais para uma acção pedagógica coordenada. (CPP2010)

Em síntese, o reposicionamento, em 2010, dos professores no mesmo Grande Grupo, 2, parece contribuir para uma uniformização do grupo profissional, esbatendo a forte discrepância que na classificação anterior havia. Contudo, a análise mais substantiva dos descritores de cada subgrupo revela uma profunda diferenciação no que à produção e uso do conhecimento profissional e relação com a "clientela", os alunos, diz particular respeito, entre outras dimensões da prática profissional docente. Numa leitura vertical, encontram-se nas posições de topo os docentes do ensino superior, assumidamente produtores e claramente distanciados relacionalmente dos 
alunos, estando no outro extremo os professores do $1^{\circ} \mathrm{CEB}$ e educadores de infância, cuja ação se centra nas pessoas dos alunos, numa iniciação a áreas de saber gerais, que mobilizam para o efeito. Os professores em posições intermédias têm, nos descritores da sua ação, forte relação com o domínio de áreas disciplinares, com enunciados que distinguem as didáticas, muito embora na última versão tenham visto reforçada a dimensão pedagógica do seu trabalho.

\section{Notas finais}

Os professores distinguem-se e são distinguidos de outros grupos profissionais pela posição que ocupam nas classificações das profissões, assim como nos sentidos que as mudanças de posições - ascendentes ou descendentes - assumem a cada revisão dessas classificações. Os professores, nas suas práticas profissionais nas escolas, nas lutas sindicais, pelas pertenças associativas e organizativas, entre outras acções, mais ou menos (in)formais, definem socialmente as suas posições no sistema educativo face às famílias, comunidades e comunicação social, e, ainda, nas classificações profissionais. Retomando Costa (1998), as classificações

(...) não são apenas mapas cognitivos da sociedade, modos de descreverem a envolvente social e de nela se orientarem. São isso mas são também juízos recíprocos, avaliações positivas e negativas, estratégias de afirmação e estigmatização, disputas e gostos, concorrência de estilos, lutas de poderes, processos de construção e destruição de identidades. (p. 67)

Os resultados da presente análise indicam que, a par de uma aproximação dos níveis de qualificação dos professores e do posicionamento nas classificações nacionais e internacionais das profissões, outros elementos contribuem para a uniformização, como a estatização da atividade docente e a monopolização da tutela como (quase) única entidade empregadora, entre outros aspetos, como a feminização, discutidos em análises anteriores (Campos, 2014). Em sentido inverso, encontram-se os elementos de diferenciação interna, como a distribuição dos professores por níveis de ensino, segundo os níveis de qualificação dos professores, vias e instituições de formação (Campos, 2014).

Pode então afirmar-se que, embora haja um discurso relativamente disseminado em torno de uma homogeneização do grupo profissional, 
reforçado por movimentos coletivos que nos últimos anos marcaram a afirmação pública dos professores em Portugal (Pereira, 2009; Resende et al., 2014; Stoleroff \& Pereira, 2009), os professores são (considerados) distintos nas funções que desempenham, consoante os níveis e ciclos de ensino. A análise permitiu demonstrar que há uma linha de diferenciação que se prende com o posicionamento que têm relativamente à produção/aplicação do conhecimento. No topo, os "docentes" académicos, produtores e disseminadores de conhecimento por si produzido, definidores dos cursos de formação; na base, os "professores" e "educadores" que junto dos alunos se ocupam da inciação às estruturas de conhecimento formal científico e desenvolvimento de competências de âmbito social e cultural.

Pode concluir-se que no processo de profissionalização dos professores em Portugal se verifica uma tendência simultaneamente de diferenciação e uniformização do grupo profissional (Campos, 2014). Essa dupla tendência espelha-se e é simultaneamente espelhada nas classificações das profissões. A análise do reposicionamento dos professores na classificação das profissões permitiu, portanto, melhor compreender a presente etapa de profissionalização dos professores em Portugal como avanço do grupo profissional dos professores no seu processo de profissionalização, se se considerar o movimento ascendente - a afirmação da crescente especialização no interior do grupo, com emergência e fixação de novos subgrupos em virtude de vias mais especializadas e avançadas de formação de professores, resultantes nomeadamente da alteração dos níveis de qualificação correspondentes à habilitação para a docência fixados no $2^{\circ}$ ciclo de formação do ensino superior.

Retomando Abbott (1988), a análise das profissões implica o desenvolvimento de uma abordagem dinâmica da profissionalização dos grupos, que, mesmo quando tomados como um todo, se pautam por uma segmentação interna dos profissionais que os constituem. Concluímos que, analiticamente, revela-se particularmente relevante a análise das classificações das profissões, nomeadamente pela possibilidade de análise dos grupos profissionais, sobretudo no que toca aos elementos distintivos face aos outros grupos profissionais, mas também pelas distinções internas, como vimos. O uso das classificações das profissões no quadro da análise dos grupos profissionais e dos respetivos processos de profissionalização 
permite assim que melhor se compreenda a permanência de dicotomias que têm traçado estes processos (Dubar, 1991), que traduzem as oposições entre o manual e o intelectual, o produtor e o reprodutor, o especialista ou perito e o executante que se encontra "no terreno".

\section{Notas}

1 Para a pesquisa em curso, a discussão sobre os professores enquanto grupo integrado nas "semiprofissões" será retomada em etapa ulterior, no sentido de melhor compreender o modo como os diversos intervenientes na afirmação e visibilidade social deste grupo profissional, investigadores incluídos, têm contribuído para o processo de profissionalização do grupo.

2 Na sua revisão da produção sociológica em torno do conhecimento profissional e as suas "novas" dimensões analíticas, Swidler e Arditti (2008) indicam os trabalhos de Abbott, em particular a sua publicação de 1988, como uma das propostas mais interessantes, na medida em que coloca o conhecimento no centro da definição das profissões, designadamente na definição da sua respetiva jurisdição - como referem: "'An academic knowledge system allows a profession to defend its jurisdiction, in part by more clearly defining borders" (Swidler \& Arditi, 2008, p. 188). Swidler e Arditti (2008), num artigo mais recente que retoma o de 1994, debruçamse sobre o alargamento do conceito de conhecimento, que, com a expansão do quadro conceptual, passou a incluir, nos trabalhos mais recentes, a análise de tipos de conhecimento formal e informal (Swidler \& Arditi, 2008, p. 184).

3 Para a compreensão do processo de profissionalização dos professores, Tardif (2013) assinala a importância da comparação entre países e regiões, indicando diferenças analíticas significativas a considerar.

4 Das diferentes modalidades que o associativismo profissional pode assumir, são, no caso dos professores em Portugal, relevantes as associações sindicais e as associações de direito privado, mais facilmente identificadas como associações de professores, excluindo-se as associações públicas, as associações patronais e as ordens profissionais.

5 A Organização Internacional do Trabalho (OIT) recomendou então aos paísesmembros as respetivas atualizações. Esta orientação foi reforçada pela publicação da recomendação 2009/824/CE da Comunidade Europeia, sublinhando-se a necessidade de estatísticas comparáveis relativamente às profissões, para a análise produzida em cada um dos estados-membros.

6 Os objetivos estatísticos da atual CPP2010 prendem-se essencialmente com a dotação do sistema estatístico nacional de uma classificação das profissões que se enquadre nas classificações internacionais e que se ajuste simultaneamente à realidade portuguesa, entre outros aspetos de natureza mais técnica. Para além dos objetivos estatísticos, destaca-se ainda outro, complementar, e que se prende com a definição de perfis profissionais. 
7 Já na adaptação da classificação internacional CITP-88 (Classificação Internacional Tipo Profissões), que introduziu uma estrutura muito distinta da anterior, a CITP-68, uma das diferenças foi precisamente o reconhecimento de "a emergência das profissões técnicas intermédias, agora autonomizadas no grande grupo 3 , constituindo um caso paradigmático do esforço de actualização da CITP-88 face às mudanças do tecido sócio-profissional das sociedades contemporâneas" (Lima, Dores, \& Costa, 1991, p. 48).

\section{Referências}

Abbott, A. (1988). The system of professions. An essay on the division of expert labor. Chicago: University of Chicago Press.

Abbott, A. (1991). The order of professionalization. An empirical analysis. Work and Occupations, 4, 355-384.

Abrantes, P., \& Sebastião, J. (2010). Portões que se abrem e que se fecham. Processos de inclusão e segregação nas escolas públicas portuguesas. In A. Dornelas, L. Oliveira, L. Veloso, \& M. D. Guerreiro (Orgs.), Portugal invisível (pp. 75-93). Lisboa: Editora Mundos Sociais.

Afonso, N. (2008). Políticas públicas da educação das crianças dos 0 aos 12 anos. In I. Alarcão (Coord.), A educação das crianças dos 0 aos 12 anos (pp. 29-43). Lisboa: CNE.

Bourdoncle, R. (1993). La professionnalisation des enseignants: Les limites d'un mythe. Revue Française de Pédagogie, 105, 183-109.

Campos, B. P. (2002). Políticas de formação de profissionais de ensino em escolas autonómas. Santa Maria da Feira: Edições Afrontamento.

Campos, J. (2014). Profissionalização dos professores em Portugal: Tendências e especificidades. In B. P. Melo, A. M. Diogo, M. Ferreira, J. T. Lopes, \& E. E. Gomes (Orgs.), Entre crise e euforia: Práticas e políticas educativas no Brasil e em Portugal (pp. 197-221). Porto: Universidade do Porto.

Carapinheiro, G., \& Rodrigues, M. L. (1998). Profissões: Protagonismos e estratégias. In J. M. Viegas \& A. F. Costa (Orgs.), Portugal, que modernidade? (pp. 147164). Oeiras: Celta.

Carvalho, T., Santiago, R., \& Caria, T. (Eds.). (2012). Grupos profissionais, profissionalismo e sociedade do conhecimento. Tendências, problemas e perspectivas. Porto: Edições Afrontamento.

Costa, A. F. (1998). Classificações sociais. Leituras, 2, 65-75.

Dubar, C. (1991). La socialisation. Construction des identités sociales et profissionelles. Paris: Armand Colin.

Estrela, T. (2014). Velhas e novas profissionalidades, velhos e novos profissionalismos: Tensões, paradoxos, progressos e retrocessos. Investigar em Educação, 2, 530. 
Evetts, J. (2003). The sociological analysis of professionalism: Occupational change in the modern world. International Sociology, 18(2), 395-415.

Gonçalves, C. M. (2007/08). Análise sociológica das profissões: Principais eixos de desenvolvimento. Sociologia, 17/18, 177-223.

Lanthaume, F. (2006). Mal-estar docente ou crise do ofício: Quando o "belo trabalho" desaparece e é preciso "trabalhar de corpo e alma". Fórum Sociológico, 15/16, 141-156.

Larson, M. S. (1977). The rise of professionalism. A sociological analysis. London: University of California Press.

Larson, M. S. (1988). À propos des professionels et des experts ou comme il est peu utile d'essayer de tout dire. Sociologie et Sociétes, 2, 23-40.

Lima, P., Dores, A. P., \& Costa, A. F. (1991). Classificações de profissões nos Censos 91. Sociologia - Problemas e Práticas, 10, 43-66.

Lousada, M. A. (2004). Associações profissionais: Tradição e renovação. In J. Freire (Coord.), As associações profissionais em Portugal (pp. 21-55). Oeiras: Celta.

Nóvoa, A. (1987). Do mestre-escola ao professor do ensino primário - Subsídios para a história da profissão docente em Portugal (séculos XVI-XX). Análise Psicológica, 3, 413-440.

Nóvoa, A. (1995). O passado e o presente dos professores. In A. Nóvoa (Org.), Profissão professor. Porto: Porto Editora.

Pereira, I. (2009). Avaliação do desempenho docente e conflitos profissionais: Ensaio de um enquadramento e exploração de evidência sobre o caso português. CIES e-WorkingPapers, 58, 1-52.

Resende, J. M., Gouveia, L., \& Beirante, D. (2014). O mandato e a licença profissional à prova das mutações no Estatuto da Carreira Docente: Controvérsias em torno do mandato profissional. In B. P. Melo, A. M. Diogo, M. Ferreira, J. T. Lopes, \& E. E. Gomes (Orgs.), Entre a crise e a euforia: Práticas e políticas educativas no Brasil e em Portugal (pp. 149-72). Porto: UP.

Rodrigues, M. L. (1997). Sociologia das profissões. Oeiras: Celta.

Rodrigues, M. L. (2012). Profissões. Lições e ensaios. Coimbra: Almedina.

Roldão, M. C. (2007). Função docente, natureza e construção do conhecimento profissional. Revista Brasileira de Educação, 34, 94-181.

Sarmento, M. J. (1994). A vez e a voz dos professores - Contributos para o estudo da cultura organizacional da escola primária. Porto: Porto Editora.

Schleicher, A. (2012). Preparing teachers and developing school leaders for the 21st century. Lessons from around the world. Paris: OECD Publishing.

Sebastião, J. (1998). Os dilemas da escolaridade. In J. M. Viegas \& A. F. Costa (Orgs.), Portugal, que modernidade? (pp. 311-327). Oeiras: Celta Editora.

Sebastião, J. (2009). Democratização do ensino, desigualdades sociais e trajectórias escolares. Lisboa: Fundação Calouste Gulbenkian.

Stoleroff, A., \& Pereira, I. (2009). A reforma da carreira docente e a conflitualidade profissional: Análise da mobilização dos professores e de discursos sindicais. In P. Abrantes, A. Diogo, A. Aníbal, R. Moinhos, H. Mendes, T. Caeiro, \& L. 
Quaresma (Orgs.), Actas do Encontro Contextos Educativos na Sociedade Contemporânea (pp. 164-187). Lisboa: Secção de Sociologia da Educação da Associação Portuguesa de Sociologia.

Stoleroff, A., \& Santos, P. (2014). Entre a reafirmação da sua missão social e pública e a defesa de um Estatuto Profissional Corporativo? Impactos do gerencialismo no profissionalismo dos professores. In B. P. Melo, A. M. Diogo, M. Ferreira, J. T. Lopes, \& E. E. Gomes (Orgs.), Entre a crise e a euforia: Práticas e políticas e políticas educativas no Brasil e em Portugal (pp. 119-147). Porto: Faculdade de Letras-UP.

Swidler, A., \& Arditi, J. (2008). The new sociology of knowledge. In J. Ballantine \& J. Spade (Eds.), Schools and society. A sociological approach to education (pp. 183-190). London: Sage Publications.

Tardif, M. (2013). A profissionalização do ensino passados trinta anos: Dois passos para a frente, três para trás. Educação \& Sociedade, 34(123), 551-571

Wilensky, H. (1964). The professionalization of everyone? American Journal of Sociology, 70, 137-158. 


\section{PROFESSIONALIZATION OF TEACHERS: RE-POSITIONING IN THE CLASSIFICATIONS OF PROFESSIONS}

\section{Abstract}

The education and training of the population is nowadays an important task. Political decision is not made without measuring educational outcomes (Schleicher, 2012). Therefore, there is an increasing demand in what teacher performance is concerned (Lanthaume, 2006; Schleicher, 2012). The text is part of a wider study on teachers in the Portuguese educational system. In the analysis made, the available knowledge on the process of teacher professionalization in Portugal was enhanced. The analysis of teachers' professional group has been developed in connection with its professionalization process, in particular the questions around the differentiation processes and internal homogenization, focusing the analysis on the (re)placement of teachers in the classification of professions. Methodologically, the basic sources for the descriptors of groups of classifications of professions are the ones expressed in international and national classifications.

Keywords

Teachers; Professionalization; Professional classifications

\section{PROFESSIONNALISATION DES ENSEIGNANTS : RE-POSITIONNEMENT DANS LES CLASSIFICATIONS DES PROFESSIONS}

\section{Résumé}

L'éducation et la formation de la population occupe dans les sociétés contemporaines une place prépondérante. Actuellement, la décision politique ne dispense pas la mesure des résultats éducatifs (Schleicher, 2012). II ya donc un besoin accru à l'égard de la performance professionnelle des enseignants (Lanthaume, 2006; Schleicher, 2012). Ce texte met l'accent sur 
une partie d'une recherche plus vaste menée autour des enseignants dans le système éducatif portugais. L'analyse développée cherché à contribuer à l'approfondissement des connaissances sur le processus de professionnalisation des enseignants au Portugal. On analyse du groupe professionnel des enseignants, dans le cadre de son processus de professionnalisation, en particulier les interrogatoires et des interpellations autour des processus de différenciation et d'homogénéisation des préoccupations internes abordées dans ce texte, en prenant soin analytiquement le (re)positionnement les enseignants dans la classification des professions. Méthodologiquement ont été identifiés comme sources principales de métiers classements nationaux et internationaux.

Mots-clé

Enseignants; Professionnalisation; Les classifications de professions

Recebido em janeiro/2016 Aceite para publicação em outubro/2016

i Departamento de Ciências Humanas e Sociais, Escola Superior de Educação de Lisboa, Instituto Politécnico de Lisboa/ Centro de Investigação e Estudos de Sociologia (CIES-IUL), Portugal.

Toda a correspondência relativa a este artigo deve ser enviada para: Joana Campos, Escola Superior de Educação de Lisboa, Campus de Benfica do IPL, 1549-003 Lisboa, Portugal. E-mail: jcampos@eselx.ipl.pt 